\title{
SÍNTESE E CARACTERIZAÇÃO DE COMPLEXOS DE COBALTO (II) COM LIGANTES ORGÂNICOS E AVALIAÇÃO ANTIMICROBIANA
}

\author{
AUTORES: Taniel Ferreira da Cruz ${ }^{1}$ \\ Geziel Rodrigues de Andrade ${ }^{2}$ \\ Geilson Rodrigues da Silva ${ }^{3}$ \\ Camila Santos Suniga Tozatti ${ }^{4}$ \\ Lis Regiane Vizolli Favarin ${ }^{5}$
}

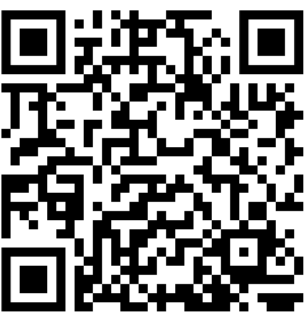

DIRECCIÓN PARA CORRESPONDENCIA: tanielfc86@hotmail.com

Fecha de recepción: 23/08/2018

Fecha de aceptación:

\section{RESUMO}

A Química Inorgânica Medicinal é uma das áreas da Química de Coordenação que vem apresentando avanços na elucidação de novos fármacos com atividade biológica oriundos de complexos metálicos. Diante disso, o presente estudo teve como objetivos sintetizar dois complexos de cobalto com os ligantes 1-(1-feniletilideno)Carbonohidrazida (LDC) e com o ligante 1,10-Fenantrolina, realizar as caracterizações espectroscópicas e termogravimétrica, assim como, avaliar a atividade antibacteriana do ligante e dos complexos frente à bactéria Escherichia coli. Realizou-se a síntese de dois complexos a partir da adaptação da rota sintética disponível na literatura. Os complexos obtidos foram caracterizados por espectroscopia na região do Ultravioleta-Visível, bem como, pela Espectroscopia no Infravermelho e pela Termogravimetria. A atividade biológica ocorreu in vitro pelo método de difusão em disco, frente a cepa bacteriana Escherichia coli. O LDC apresentou duas bandas na região do ultravioleta $(180 \mathrm{~nm}-380 \mathrm{~nm})$, não sendo verificadas absorções na região do visível $(380 \mathrm{~nm}-780 \mathrm{~nm})$, pois o composto não

\footnotetext{
${ }^{1}$ Licenciado em Química pelo Instituto Federal de Ciência e Tecnologia de Mato Grosso do Sul- IFMS(Brasil). Professor Celetista da Escola Estadual Leontino Alves de Oliveira. Rio Negro, Mato Grosso do Sul, Brasil. E-mail: tanielfc86@hotmail.com

${ }^{2}$ Licenciado em Química pela Universidade Estadual de Mato Grosso do Sul. Mestre em Química pela Universidade Federal da Grande Dourados. Doutorando em Química pela UFMS. Professor EBTT do Instituto Federal de Mato Grosso do Sul- Campus Coxim. Coxim, Mato Grosso do Sul, Brasil. E-mail: geziel.andrade@ifms.edu.br

${ }^{3}$ Licenciado em Química pelo Instituto Federal de Ciência e Tecnologia de Mato Grosso do Sul. Mestrando em Ensino de Ciências pela Universidade Federal de Mato Grosso do Sul. Campo Grande, Mato Grosso do Sul, Brasil. E-mail: geilsonrodrigues367@gmail.com.

${ }^{4}$ Possui graduação em Licenciatura Plena em Química pela Universidade do Oeste Paulista, graduação em Tecnologia em Processos Químicos Industriais pela Universidade do Oeste Paulista, mestrado em Química pela Universidade Federal de Mato Grosso do Sul e doutorado em Química pela Universidade Federal de Mato Grosso do Sul. Professora do colégio militar de Campo Grande. Campo Grande, Mato Grosso do Sul, Brasil. E-mail: camilasuniga@gmail.com.

${ }^{5}$ Graduada em Química pela Universidade Estadual do Mato Grosso do Sul (2011), Mestre em Química pela Universidade Federal da Grande Dourados (2012-2014), doutoranda em Química pela Universidade Federal De Mato Grosso do Sul. Campo Grande, Mato Grosso do Sul, Brasil. E-mail: lisregiane @ hotmail.com.
} 
Autor1, Autor2, Autor3

apresentou cor. Verificou-se que na região do infravermelho, a banda dos complexos é deslocada para região de maior energia (maior número de onda), isso indica que o íon metálico esteja coordenado ao oxigênio da $\mathrm{C}=\mathrm{O}$. As avaliações termogravimétricas permitiram indicar a real composição dos complexos sintetizados. O ligante não apresentou inibição diante da bactéria, o complexo I e o complexo II demonstraram atividade frente à cepa bacteriana .

PALAVRAS CHAVE: Compostos de Coordenação, Transição Eletrônica, Espectroscopia no Infravermelho.

\section{SYNTHESIS AND CHARACTERIZATION OF COBALT (II) COMPLEXES WITH ORGANIC BINDERS AND ANTIMICROBIAL EVALUATION}

\section{ABSTRACT}

Medicinal Inorganic Chemistry is one of the areas of Coordinating Chemistry that has been presenting advances in the elucidation of new pharmaceuticals with biological activity from metallic complexes. In view of this, the objective of this study was to synthesize two cobalt complexes with the ligands 1-(1-Feniletilideno) Carbonohidrazida (LDC) and with the ligand 1.10-phenanthroline, to perform the spectroscopic and thermogravimetric characterisations, thus how to evaluate the antibacterial activity of the ligand and the complexes in the face of the Escherichia coli bacterium. The synthesis of two complexes was carried out from the adaptation of the synthetic route available in the literature. The complexes obtained were characterized by spectroscopy in the ultraviolet-visible region, as well as by infrared spectroscopy and thermogravimetry. The biological activity occurred in vitro by the method of diffusion in disk, in front of bacterial strain Escherichia Coli. The LDC presented two bands in the Ultraviolet region $(180 \mathrm{~nm}-380 \mathrm{~nm})$, not being verified absorption in the region of the visible $(380 \mathrm{~nm}-780 \mathrm{~nm})$, because the compound did not present color. It was found that in the infrared region, the band of the complexes is shifted to Higher energy region (greater wave number), this indicates that the metallic ion is coordinated to the oxygen of $\mathrm{C}=\mathrm{O}$. The Termogravimétricas evaluations allowed to indicate the actual composition of the synthesized complexes. The ligand did not present inhibition before the bacterium, complex I and complex II demonstrated activity in the face of bacterial strain.

KEYWORDS: Coordination Compounds, Electronic Transition, Infrared Spectroscopy.

\section{INTRODUÇÃO}

A Química de Coordenação teve impulso com o advento das técnicas espectroscópicas de caracterização, permitindo o desenvolvimento de linhas de investigações aplicados a sociedade e dentre essas, ocorre a Química Inorgânica Medicinal que investiga o desenvolvimento de novos fármacos com atividade biológica oriundos de complexos metálicos. Neste contexto destacam-se os seguintes complexos com atividade biológica: de platina com propriedades antitumorais, os de arsênio no tratamento da sífilis, os antiparasitários de antimônio e os de bismuto como antibacterianos (WARAD, 2013; BERALDO, 2012).

Dentre os alvos de pesquisas científicas tem-se os complexos de Cobalto que apresentam vantagens em relação aos demais, pois apresentam alta estabilidade aquosa, condição primordial devido as bactérias também apresentarem água na sua constituição, com isso tais complexos tornam-se promissores agentes antimicrobianos (CHANG, et al. 2010). 
Em relação a natureza do ligante, Rizzotto (2012) indicou que este é um dos principais critérios para uma atividade antimicrobiana, sendo que os ligantes bidentados (quelato) geralmente apresentam melhor atividade do que ligantes monodentados. Diante disso propõe-se o ligante 1(1-feniletilideno) carbonohidrazida (LDC) que age primordialmente de forma bidentada, constituindo-se como um ligante potencial para a síntese de complexos que podem apresentar atividade antimicrobiana. Ainda neste aspecto, o LDC apresentam semelhança estrutural com as tiosemicarbazonas, as quais são conhecidas por apresentarem atividades biológicas, destacando a atividade antimicrobiana (TOZATTI, 2016). Além disso, Osowole, Ekennia, Osukwe, (2013) contribuem com essa discussão ao apontarem que os ligantes quando apresentam átomos de $\mathrm{N}$ e O, doadores, mostram melhor atividade antimicrobiana estando na forma de complexos.

Diante dessas discussoes apresentadas, o presente estudo buscou realizar a síntese de dois complexos com o íon metálico Co (II), bem como, caracterizar via espectroscopia e termogravimetria ambos complexos, assim como, verificar o potencial de atividade antimicrobiano.

\section{DESENVOLVIMENTO}

\section{Materiais e Métodos}

Todos os reagentes e solventes utilizados foram de grau P.A e o ligante (LDC) não foi previamente purificado. Os complexos obtidos também não foram purificados para as análises e testes de atividade biológica.

A cepa padrão apresentou controle de qualidade ATCC (American Type Culture Collection). Utilizou-se de discos com o antibiótico Amoxicilina (com concentração de $10 \mu \mathrm{g}$ por disco) como controle positivo, o reagente DMSO-Dimetilsulfóxido $\left(\mathrm{CH}_{3}\right)_{2} \mathrm{SO}$ foi utilizado como controle negativo e todos os testes foram realizados em triplicatas.

A atividade antibacteriana ocorreu em três compostos, o complexo I, o complexo II e o ligante LDC, diante da bactéria Escherichia coli. O método utilizado para detectar a ocorrência de inibição do crescimento do microrganismo foi o método de difusão em ágar - técnica do disco. Os compostos foram impregnados em discos de papel de filtro de $6 \mathrm{~mm}$, para a realização dos testes de atividade antimicrobiana.

\section{Métodos de Síntese}

Para a obtenção do complexo I utilizou-se apenas o ligante LDC, enquanto que na síntese do complexo II, além do LDC foi utilizado a fenantrolina (Phen) como ligante.

O (LDC) foi obtido a partir da reação entre acetofenona e carbonohidrazida em estequiometria 1:1 respectivamente, conforme apresentado na literatura (QIAO et al., 2009). Foi utilizado o reagente 1,10 Fenantrolina da Merck como ligante para a síntese dos complexos. A partir dos ligantes sintetizou-se dois novos complexos de cobalto II conforme adaptação de método de síntese de Boltz (2011).

\section{Síntese do Complexo de Cobalto com o LDC (Complexo I)}

O complexo I foi obtido na proporção 1:1, na concentração de 0,2 mmol, com 0,047 g de cloreto de cobalto hexaidratado $\left[\mathrm{Co}\left(\mathrm{H}_{2} \mathrm{O}\right)_{6}\right] \mathrm{Cl}_{2}$ e dissolveu-se em $5 \mathrm{~mL}$ de metanol $\left(\mathrm{CH}_{3} \mathrm{OH}\right)$ em 
Autor1, Autor2, Autor3

agitação por 10 minutos, para o acrescimento de $0,037 \mathrm{~g}(0,2 \mathrm{mmol})$ do LDC, a solução de partida em agitação constante (temperatura ambiente), o sistema foi posto em repouso e depois de 4 dias formou-se um sólido roxo escuro.

\section{Síntese do complexo de Cobalto com o ligante LDC e com o ligante Phen (Complexo II)}

Obteve-se o complexo 2 na proporção 1:1, com a concentração de 0,2 mmol, com 0,047 g de cloreto de cobalto hexaidratato, $\left[\mathrm{Co}\left(\mathrm{H}_{2} \mathrm{O}\right)_{6}\right] \mathrm{Cl}_{2}$ e dissolveu-se em $5 \mathrm{~mL}$ de metanol $\left(\mathrm{CH}_{3} \mathrm{OH}\right)$, a essa solução que denominamos como (solução 1). Em seguida com 0,038 g (0,2 mmol) do ligante 1,10 fenantrolina, foram dissolvidos em $5 \mathrm{~mL}$ de metanol $\left(\mathrm{CH}_{3} \mathrm{OH}\right)$, a essa solução que denominamos de (solução 2). Misturou-se homogeneamente as soluções (solução 1 e 2) sob agitação. Por fim $0,039 \mathrm{~g}(0,02 \mathrm{mmol})$ do ligante LDC foram adicionados ao sistema deixando reagir por 4 horas. Após 4 dias de repouso um sólido esverdeado escuro foi formado.

\section{Métodos de Caracterização}

\section{Análise por Espectroscopia UV-Vis}

Os espectros de absorção eletrônica foram obtidos na região do UV-Vis no espectrofotômetro de absorção UV-Vis Cary 50 (Varian). Os solventes utilizados nessas análises foram o metanol $\left(\mathrm{CH}_{3} \mathrm{OH}\right)$ e o Dimetilsulfóxido $\left(\mathrm{CH}_{3}\right)_{2} \mathrm{SO}$, com uma faixa de varredura entre 200 e $800 \mathrm{~nm}$.

\section{Análise por Espectroscopia no Infravermelho (FT-IR)}

Os espectros vibracionais na região do infravermelho foram caracterizados no espectrofotômetro FTIR 41000 - Jasco. As medidas dos complexos ocorrem na faixa de 4000 a $400 \mathrm{~cm}^{-1}$, as amostras foram preparadas por dispersão em brometo de potássio $(\mathrm{KBr})$ e prensadas formando pastilhas.

\section{Análise Termogravimétrica (TG)}

As avaliações Termogravimétricas foram realizadas no equipamento PerkinElmer Simultaneos Thermal Analyser STA 6000. As análises foram realizadas em ar atmosférico, com razão de aquecimento de $10^{\circ} \mathrm{C} / \mathrm{min}$. A temperatura de aquecimento variou de $30^{\circ} \mathrm{C}$ a $960^{\circ} \mathrm{C}$.

\section{Atividade Biológica}

\section{Preparação do Meio de Cultura}

Para a preparação dos meios de cultura para a cepa Escherichia coli ATCC 53338, utilizou-se o Ágar Müeller-Hinton. Esterilizou-se os materiais utilizados na autoclave à temperatura de $121^{\circ} \mathrm{C}$ durante 15 minutos (CLSI, 2011).

\section{Preparação das soluções empregadas nos testes de atividade antimicrobiana}

As soluções foram preparadas na concentração de $\mathrm{mg} / \mathrm{mL}$ e o solvente empregado foi o Dimetilsulfóxido. Os testes não objetivaram estipular uma concentração precisa para os complexos em cada disco, mas concentrar o máximo de composto em cada disco para investigar se os complexos apresentam atividade antibacteriana (LOPES, 2016). 


\section{Preparação da solução com o complexo I e o complexo II e da solução com o ligante LDC}

Com $50 \mathrm{mg}$ de ambos os complexos, foram dissolvidos em 800 microlitros de Dimetilsulfóxido. Para a impregnação do complexo, pipetou-se 5 microlitros da solução sendo adicionados em cada disco e dispostos na estufa (SX1.2, DTME), em uma temperatura de $50{ }^{\circ} \mathrm{C}$ para secagem. A solução preparada com o ligante LDC seguiu a mesma rota.

\section{Inoculação das Bactérias}

Com a utilização de um swab esterilizado, espalhou-se o microorganismo de forma uniforme, em toda a superfície estéril do ágar, girando a placa aproximadamente $60^{\circ}$ para distribuir o inoculo uniformemente (CLSI, 2011; MADIGAN et al, 2016).

\section{Aplicação dos discos às placas}

Cada placa foi composta por 5 discos respectivamente: um disco com o controle positivo, um com o controle negativo, um com o complexo I e um com complexo II. As placas foram vedadas com parafilme, invertidas e deixadas na incubadora por 24 horas à uma temperatura de $37{ }^{\circ} \mathrm{C}$ (CLSI, 2011; MADIGAN et al. 2016).

\section{RESULTADOS E DISCUSSÃO}

Após as sínteses dos complexos foram obtidos dois sólidos amorfos utilizando a metodologia de síntese para os complexos I (rendimento de $56 \%$ ) e II (rendimento de 68\%). Considerando a obtenção do complexo na estequiometria proposta.

\section{Espectroscopia no UV-Vis}

O comportamento espectroscópico na região do ultravioleta e visível foi averiguado para o LDC (Figura 1 - a e b), complexo 1, (Figura 2 - a e b) e complexo 2 (Figura 3 - a e b).

O LDC apresentou duas bandas na região do ultravioleta (180 nm - $380 \mathrm{~nm}$ ) (Figura 1), uma em $209 \mathrm{~nm}$ referente a transições do tipo $\pi-\pi^{*}$ do anel aromático e uma outra em $273 \mathrm{~nm}$ (Figura 1) a qual está relacionada as transições do tipo $n-\pi^{*}$ devido à presença de átomos com pares de elétrons livre ( $\mathrm{N}$ e O $)$. Transições do tipo $n-\pi^{*}$ são menos energéticas do que as do tipo $\pi-\pi^{*}$ sendo encontradas em comprimentos de onda maiores. Não foram verificadas absorções na região do visível (380 nm - $780 \mathrm{~nm}$ ) para o LDC, pois o composto não apresentou cor.

(a)

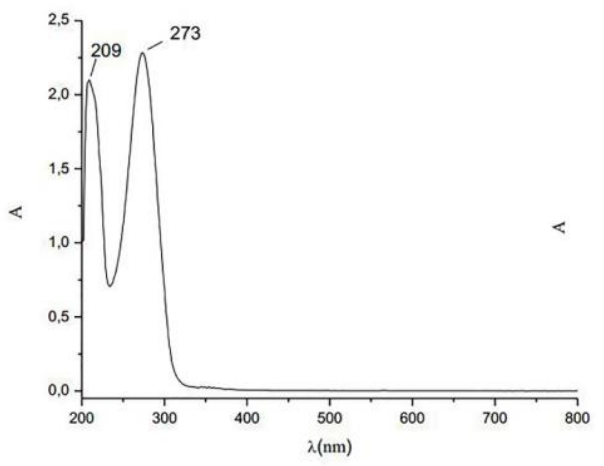

(b)

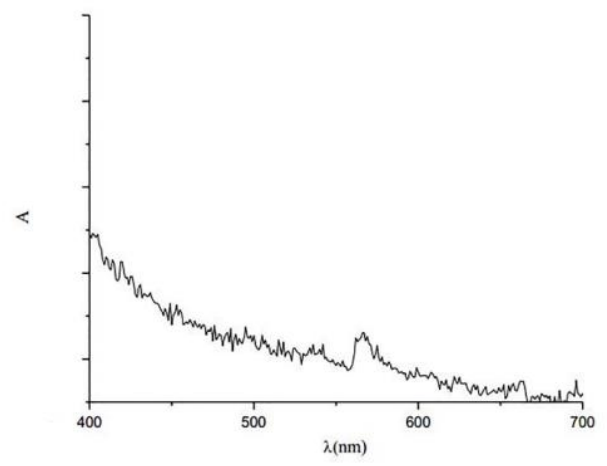


Autor1, Autor2, Autor3

Figura 1: Espectros de absorção no UV - Vis do composto LDC: (a) 200 nm-800 nm. (b) 400 $\mathrm{nm}-700 \mathrm{~nm}$. Fonte: Elaborado pelos autores.

As transições eletrônicas do tipo n- $\pi^{*}$ é observada em 298 nm para o complexo 1 (Figura 2) e em $270 \mathrm{~nm}$ para o complexo 2 (Figura 3). Em comparação com o espectro do LDC as bandas sofreram deslocamentos. Para o complexo 1 foi um deslocamento do tipo batocrômico (para região de menor energia; 273-298 nm) e para o complexo 2 (pequeno deslocamento) foi do tipo hipsocrômico (para região de maior energia; 273-270 nm). Isso sugere a coordenação do átomo de cobalto (II) com os átomos doadores do LDC. Foram verificadas absorções na região do visível para ambos os complexos (Figura 2 e 3). Essas absorções são oriundas de transições do tipo d-d que é comum para os metais da primeira série de transição (com exceção do zinco). Complexos que apresentam esse tipo de transição são coloridos.

(a)

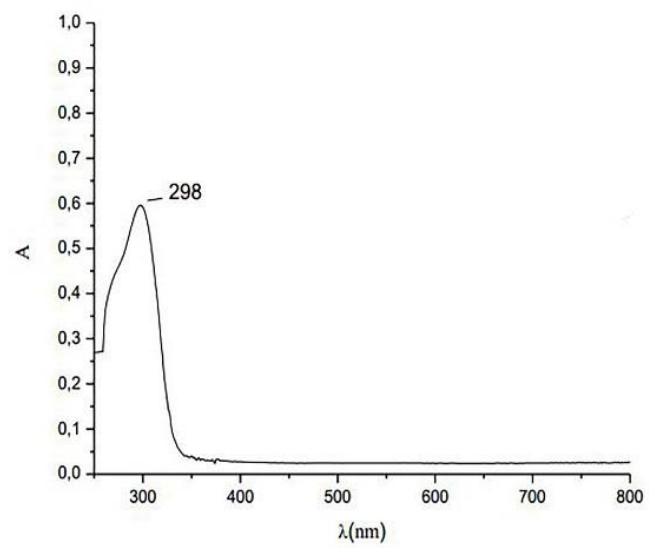

(b)

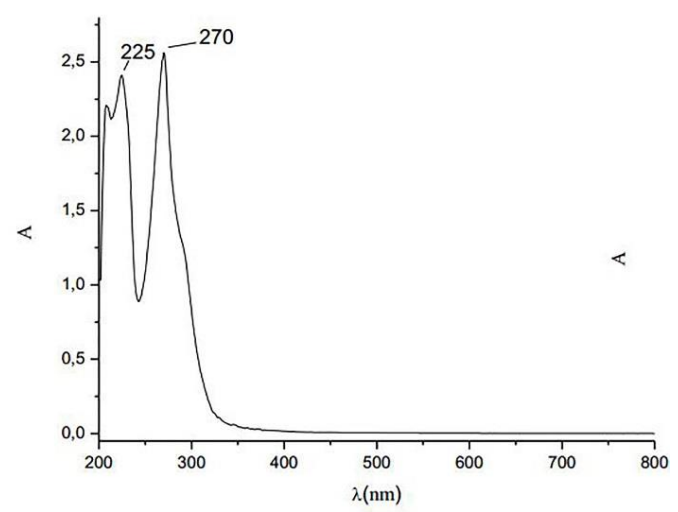

Figura 2: Espectros de absorção no UV - Vis do complexo 1: (a) $250 \mathrm{~nm}-800 \mathrm{~nm}$.

(b) $400 \mathrm{~nm}-700 \mathrm{~nm}$. (Fonte: Elaborado pelos autores).

(a)

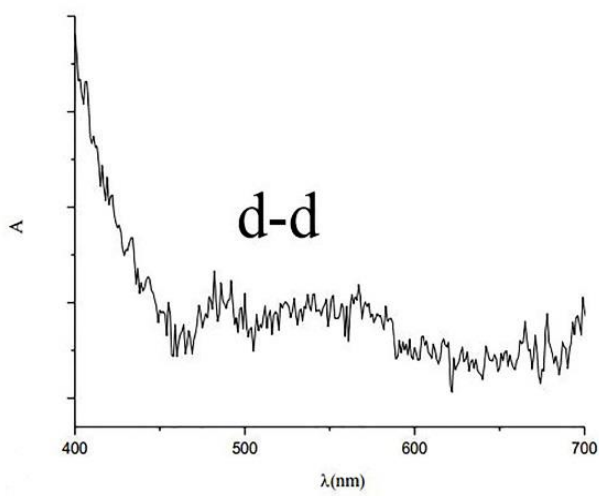

(b)

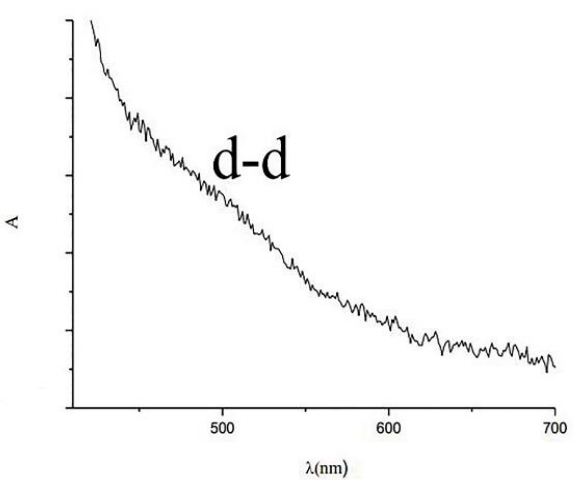


Figura 3: Espectros de absorção no UV - Vis do complexo 2: (a) $200 \mathrm{~nm}$ - $800 \mathrm{~nm}$. (b) $400 \mathrm{~nm}$ $700 \mathrm{~nm}$. (Fonte: Elaborado pelos autores).

\section{Espectroscopia no Infravermelho}

Os espectros no infravermelho para o ligante LDC, complexo 1 e complexo 2 estão dispostos na figura 4, 5 e 6 respectivamente. As bandas observadas estão entre $3323-3188 \mathrm{~cm}^{-1}$ para o ligante, é atribuído aos diferentes tipos de estiramentos axiais da ligação N-H. Em $3062 \mathrm{~cm}^{-1}$ observa-se o estiramento das ligações C-H (aromático) e em $2884 \mathrm{~cm}^{-1}$ a banda de absorção está relacionada à ligação C-H do grupo metila (alifático) a qual na literatura sempre é verificada em número de onda abaixo de $3000 \mathrm{~cm}^{-1}$ (SILVERSTEIN, WEBSTER e KIEMLE, 2006). Entre 1675 e 1495 $\mathrm{cm}^{-1}$ observa-se as bandas relacionadas ao estiramento axial do grupo carbonila $(\mathrm{C}=\mathrm{O})$, deformações angulares da ligação $\mathrm{N}-\mathrm{H}$, estiramento axial da ligação $\mathrm{C}=\mathrm{N}$ e da ligação $\mathrm{C}=\mathrm{C}$.

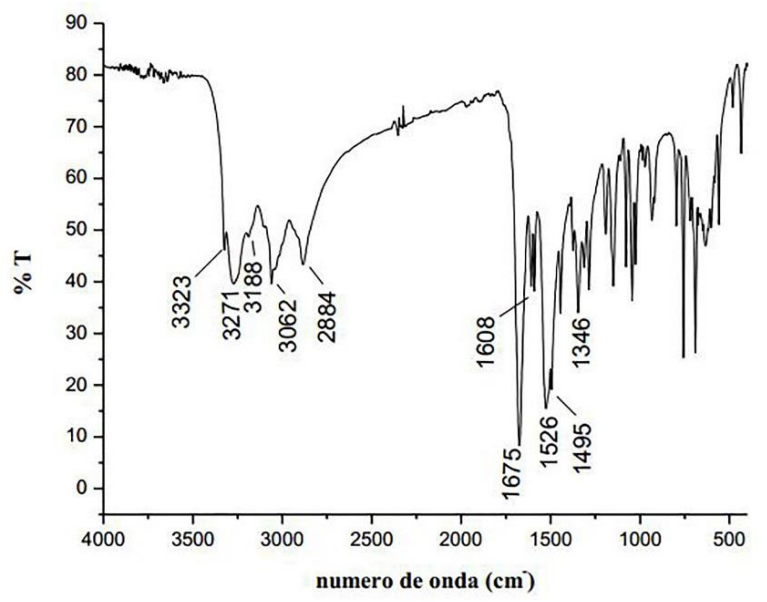

Figura 4: Espectro no infravermelho do LDC em pastilha de KBr. (Fonte: Elaborado pelos autores).

O complexo 1 apresentou as principais bandas referentes ao LDC, entretanto os valores de número de onda das bandas que envolvem processos vibrônicos de ligações com átomos de $\mathrm{N}$ e O estão deslocados em comparação com o ligante para regiões de maior energia (maior número de onda), esse deslocamento sugere a coordenação do ligante com o metal.

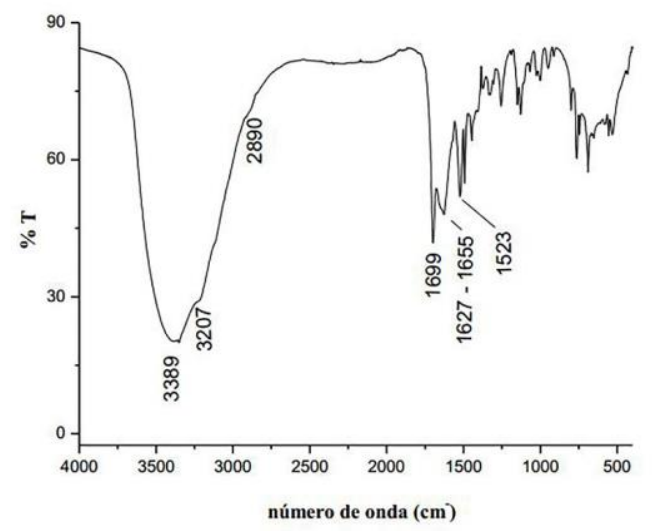


Figura 5: Espectro no infravermelho do complexo 1 em pastilha de $\mathrm{KBr}$. (Fonte: Elaborado pelos autores).

Esse efeito é verificado para o espectro do complexo 2, porém com algumas diferenças em comparação com o complexo 1 . A intensificação da banda em $1658 \mathrm{~cm}^{-1}$ referente ao estiramento axial da ligação $\mathrm{C}=\mathrm{N}$ pode estar relacionada a coordenação com o ligante Phen. Além do mais, uma banda forte em $1426 \mathrm{~cm}^{-1}$ é observada no espectro do complexo 2 a qual está relacionada as vibrações $\mathrm{C}=\mathrm{C}$ do ligante Phen coordenado ao íon metálico.

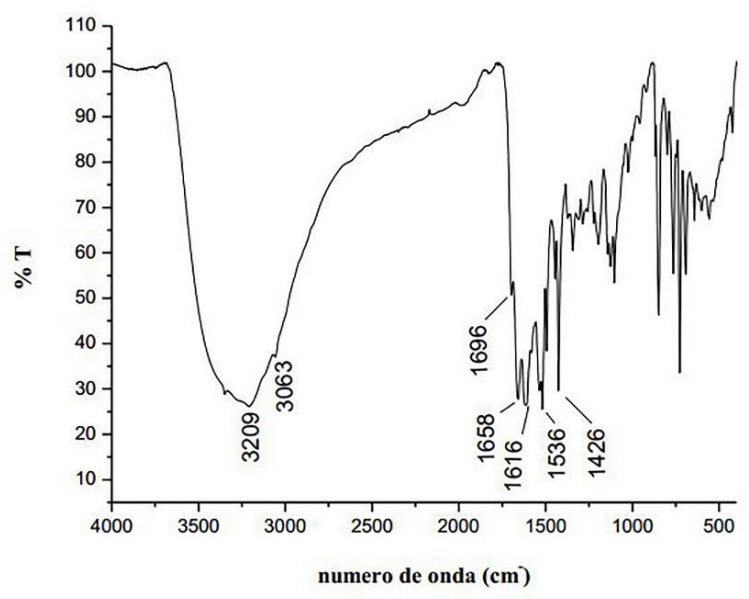

Figura 6: Espectro no infravermelho do complexo 2 em pastilha de $\mathrm{KBr}$. (Fonte: Elaborado pelos autores).

A tabela 1 apresenta as principais bandas e atribuições dos espectros no infravermelho dos compostos.

\begin{tabular}{|c|c|c|c|}
\hline Atribuições & $\mathbf{I}$ & II & III \\
\hline$v_{\mathrm{N}-\mathrm{H}}$ & $\begin{array}{l}3323- \\
3188\end{array}$ & $3389-3207$ & 3209 \\
\hline $\begin{array}{l}\mathrm{v}_{\mathrm{C}-\mathrm{H}} \\
\text { (aromático) }\end{array}$ & 3062 & encoberta & 3063 \\
\hline $\begin{array}{l}v_{\mathrm{C}-\mathrm{H}} \\
\text { (alifático) }\end{array}$ & 2884 & 2890 & encoberta \\
\hline $\begin{array}{l}v_{\mathrm{C}=\mathrm{O}}, \quad \delta_{\mathrm{N}-\mathrm{H}}, \\
v_{\mathrm{C}=\mathrm{N} \text { e }} v_{\mathrm{C}=\mathrm{C}}\end{array}$ & $\begin{array}{l}1675- \\
1495\end{array}$ & $1699-1523$ & $1696-1426$ \\
\hline
\end{tabular}

Tabela 1: Principais bandas e atribuições, $\mathrm{em} \mathrm{cm}^{-1}$, dos espectros no infravermelho para o LDC (I), complexo 1 (II) e para o complexo 2 (III) ( $v$ = estiramento axial; $\delta=$ deformação angular). (Fonte: Elaborado pelos autores). 
Na tabela acima está sumarizada todos os resultados obtidos com as análises espectroscópicas evidenciando as bandas encobertas por outros estiramentos axiais.

A figura 7 apresenta os espectros sobrepostos do LDC, complexo 1 e 2 compreendendo a região entre 1720 a $1650 \mathrm{~cm}^{-1}$, indicando as bandas de estiramento axial da carbonila para os três compostos. Verifica-se que a banda dos complexos é deslocada para região de maior energia (maior número de onda), isso indica que o íon metálico esteja coordenado ao oxigênio da $\mathrm{C}=\mathrm{O}$.

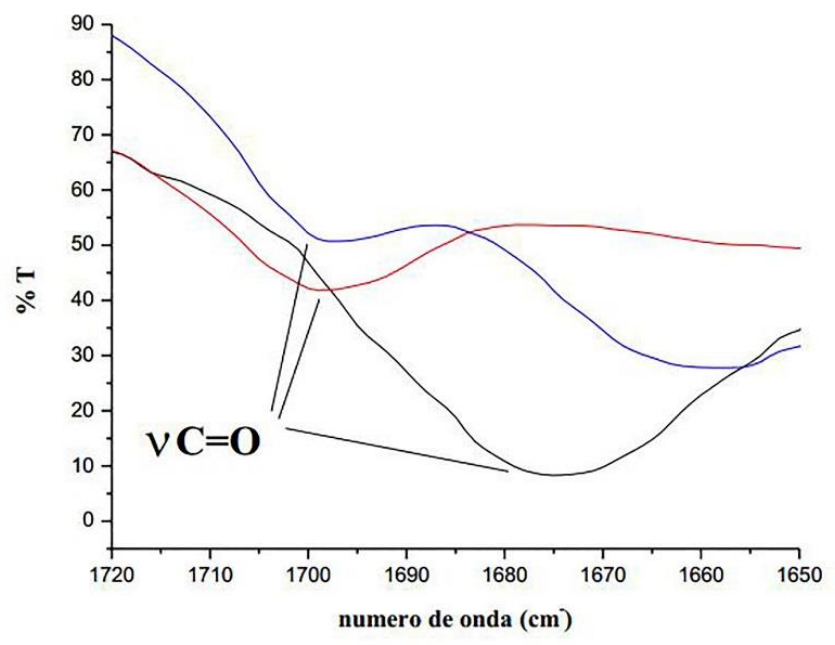

Figura 7: Espectro sobreposto no infravermelho do LDC (preto; banda em $1675 \mathrm{~cm}^{-1}$ ), complexo 1 (vermelho; banda em $1699 \mathrm{~cm}^{-1}$ ) e complexo 2 (azul; banda em $1696 \mathrm{~cm}^{-1}$ ). (Fonte: Elaborado pelos autores).

\section{Análise Termogravimétrica}

É apresentado nas figuras 8 e 9, as curvas termogravimétricas para os complexos I, II.

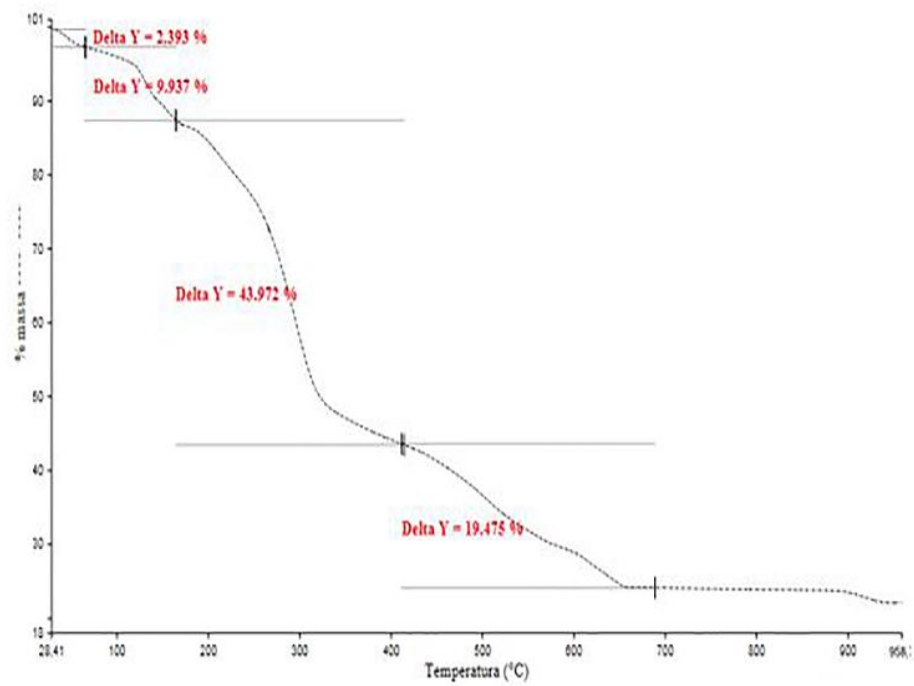


Autor1, Autor2, Autor3

Figura 8: Curva termogravimétrica para o complexo I. (Fonte: Elaborado pelos autores).

Na figura 8, é apresentado a curva Termogravimétrica para o complexo I, que apresentou massa inicial de 5,465 mg e teve a fórmula molecular proposta, [Co( $\mathrm{LDC}) \mathrm{Cl}_{2}\left(\mathrm{H}_{2} \mathrm{O}\right)$ ], a partir da decomposição térmica que ocorreu em quatro etapas. O complexo I, tem como constituinte dois ligantes áqua e dois cloretos na esfera de coordenação primária e apresenta também o LDC. A primeira perda de massa da figura 8, corresponde ao metanol, devido ás sínteses terem ocorridos em meio metanólico. Já em relação a segunda decomposição de massa corresponde a 9,937\% correspondendo à saída das águas de coordenação que apresentaram uma temperatura máxima $180^{\circ}$ C. A terceira perda de massa corresponde ao ligante LDC que apresentou 43,972\% de decomposição. E por fim a quarta perda de massa é atribuída à saída de dois cloretos que ocorreu acima de $400{ }^{\circ} \mathrm{C}$ até aproximadamente $700{ }^{\circ} \mathrm{C}$. Acima da $700{ }^{\circ} \mathrm{C}$ não ocorreu novas perdas de massa, isso manteve-se até aproximadamente $900{ }^{\circ} \mathrm{C}$. Após essa temperatura ocorre uma nova perda de massa devido às cinzas do ligante oxidadas pelo gás $\mathrm{O}_{2}$ do ar atmosférico. Sendo que o resíduo formado teve como o valor teórico de 20,4\%, resultado que se aproximou do valor real de $22,4 \%$, indicando com isso que o resíduo formado é $\mathrm{Co}_{3} \mathrm{O}_{4}$, óxido duplo devido a junção dos dois óxidos mais comuns.

A Curva Termogravimétrica do complexo II é apresentado na figura 9, que teve massa inicial de $6,742 \mathrm{mg}$ com fórmula molecular proposta de $\left[\mathrm{Co}(\mathrm{LDC})(\mathrm{PHEN}) \mathrm{Cl}_{2} 2\left(\mathrm{H}_{2} \mathrm{O}\right)\right]$, a partir da decomposição térmica em duas etapas.

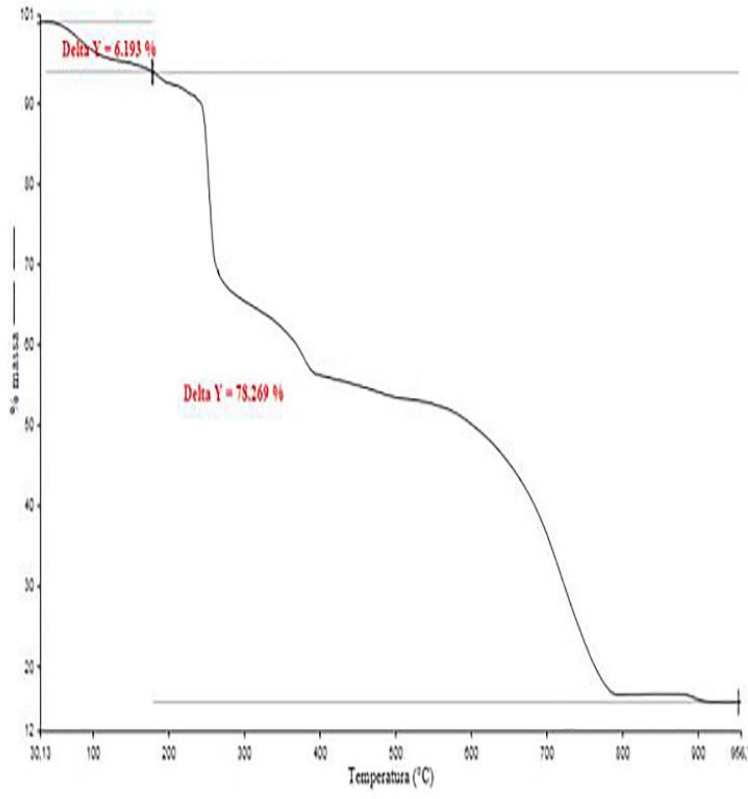

Figura 9: Curva Termogravimétrica do Complexo II. (Fonte: Elaborado pelos autores).

Na figura 9, ocorreu a perda das águas de coordenação na temperatura próxima de $200^{\circ} \mathrm{C}$, valor próximo das saídas das águas de coordenação no complexo I. Já a segunda perda de massa, apresentou o valor elevado, pois nesse intervalo ocorreu a saída dos dois ligantes, assim como, a saída dos cloros, ocorreu ainda a saída das águas correspondendo a 6,193\%, ou seja, 0,417 mg de 
massa foi decomposta. A massa do resíduo foi $1,049 \mathrm{mg}$ que é um óxido de cobalto, sendo ás informações termogravimétricas apontam que o resíduo formado é $\mathrm{Co}_{2} \mathrm{O}_{3}$ óxido de cobalto (III).

\section{Atividade Antimicrobiana}

$\mathrm{Na}$ tabela 2 apresenta-se os resultados da atividade antimicrobiana dos complexos e do ligante, estão relacionados ainda os valores médios dos halos de inibição do crescimento dos complexos e do antibiótico.

\begin{tabular}{l|l|l|l|l}
\hline Composto/cepa & \multicolumn{4}{|c}{ E. Coli } \\
\hline & $\begin{array}{l}1^{\text {a }} \text { Placa } \\
(\mathrm{mm})\end{array}$ & $\begin{array}{l}2^{\text {a }} \text { Placa } \\
(\mathrm{mm})\end{array}$ & $\begin{array}{l}3^{\mathrm{a}} \\
\text { Placa } \\
(\mathrm{mm})\end{array}$ & $\begin{array}{l}\text { Média } \\
(\mathrm{mm})\end{array}$ \\
\hline Amoxicilina & 21 & 19 & 20 & 20 \\
\hline DMSO & N.A & N.A & N.A & - \\
\hline LDC & N.A & N.A & N.A & - \\
\hline Complexo I & 22 & 24 & 22 & 22.66 \\
\hline Complexo II & 22 & 20 & 20 & 20.66 \\
\hline
\end{tabular}

Tabela 2: Resultados dos halos de inibição em (mm). * N.A= Não apresenta atividade. (Fonte Elaborado pelos autores).

Observa-se que o complexo 1 e o complexo 2 apresentaram inibição do crescimento da Escherichia coli no entanto, o ligante LDC não apresentou atividade biológica frente essa cepa.

O Dimetilsulfóxido, apresentou inibição conforme previsto e o antibiótico amoxicilina apresentou valores de halos inibitórios esperados. O antibiótico deve apresentar valores de halos entre 18 e $24 \mathrm{~mm}$ para a cepa Escherichia coli (CLSI, 2011).

A partir dos resultados, observou-se que os diâmetros dos halos formados pelo antibiótico amoxicilina foram menores que os halos apresentados tanto pelo complexo 1 quanto pelo complexo 2, o padrão utilizado apresentou média de $20 \mathrm{~mm}$ para os halos de inibição. $\mathrm{O}$ complexo 1 apresentou média $22.66 \mathrm{~mm}$ para os halos de inibição, enquanto o complexo 2 apresentou média $20.66 \mathrm{~mm}$ para os halos de inibição.

Halli, et al. (2012), por sua vez obteve resultados congruentes ao exposto acima com a síntese de complexos de cobalto (II) com ligantes derivados do benzofuran-2-carbonohidrazida e com o ligante acetofenona, que apresentaram atividade antimicrobiana frente a cepa Escherichia coli, apresentando halo de inibição de $9 \mathrm{~mm}$ de diâmetro. Os resultados obtidos apresentaram caráter qualitativo e apontaram que os novos complexos sintetizados possuem atividade antimicrobiana.

\section{CONCLUSÕES}

No presente estudo foram sintetizados dois novos complexos de cobalto (II), a partir dos ligantes 1-(1-feniletilideno)carbonohidrazida e 1,10-Fenantrolina, sendo que esses complexos foram caracterizados por meio da espectroscopia de UV-Vis e FT - IR (Infravermelho) que apontaram para a formação de dois complexos diferentes. 
Autor1, Autor2, Autor3

Já em relação a caracterização termogravimétrica, esta propiciou obter informações sobre a estabilidade e decomposição térmica dos complexos. Além disso foi possível determinar o indicativo da real composição dos complexos sintetizados, tais como o produto final e a decomposição térmica, que formou-se, possivelmente o $\mathrm{Co}_{3} \mathrm{O}_{4}$ - óxido de cobalto (II) do $\mathrm{Co}_{2} \mathrm{O}_{3}{ }^{-}$ óxido do cobalto (III).

Os resultados da avaliação qualitativa da atividade antimicrobiana demonstrou que os complexos apresentam potencial biológico, suscitando-se, assim a proposta de novos estudos em outras cepas bacterianas como perspectiva futura.

\section{REFERÊNCIAS BIBLIOGRÁFICAS}

BERALDO, H. (2012). Tendências Atuais e as Perspectivas Futuras da Química Inorgânica. Ciência $e$ Cultura, v.63, n.1, p. 29-32.

BOLTZ, M. (2011). Heterogenization of $\left[\mathrm{Cu}\left(2,2^{\prime}-\right.\right.$-bpy $\left.) \mathrm{Cl}_{2}\right]$ and $\left[\mathrm{Cu}(1,10-\right.$ phen $\left.) \mathrm{Cl}_{2}\right]$ on Polyoxometalates: New Catalysts for the Selective Oxidation of Tetralin. Chinese Journal of Catalysis, v. 32, n.5, p. 807-811.

CHANG, E. L. et al. (2010). Cobalt Complexes as Antiviral and Antibacterial Agents. Pharmaceuticals, v. 3, n.6, p. 1711-1728.

CLSI. (2011). Performance Standards for Antimicrobial Susceptibility Testing. Twenty-First Informational Supplement. CLSI document M100-S21. Wayne, PA: Clinical and Laboratory Standards Institute.

HALLI, M. B. et al. (2012). Synthesis, Characterization and Antimicrobial Screening of Metal (II) Complexes Derived From Benzofuran-2-Carbohydrazide and Acetophenone Schiff Base. International Journal of Pharma and Bio Sciences. v. 3, n. 4, p.547-557.

QIAO, Y.et al. (2009). 1-(1-Phenyletilidene)carbonohidrazide. Acta Crystallographica, v. 65, n.10, p. 384-393.

LOPES, P. M. (2016). Avaliação da atividade antimicrobiana de extratos de Dioscorea piperifolia Frente à microrganismos patogênicos. 62 f. Dissertação de Mestrado em Ciências (Química). Instituto de Química. Universidade Federal do Rio de Janeiro, Rio de Janeiro.

MADIGAN, M. T. (2016). Microbiologia de Brock. 14ª ed. Porto Alegre: Artmed.

OSOWOLE, A. A. EKENNIA, A. C. OSUKWE, A. E. (2013). Synthesis, Spectroscopic and Antibacterial Properties of Some Metal (II) Mixed Ligand Complexes of Riboflavin and 2,2'-Bipyridine. Research and Reviews: Journal of Chemistry. v. 3, n. 1, p. 32-37.

188 UNESUM-Ciencias. Publicación cuatrimestral. Vol. 1, Año 2017, No. 1 (Abril) 
RIZZOTTO, M. (2012). Metal Complexes as Antimicrobial Agents. In: BOBBARALA, V. A Search for Antibacterial Agents. Rijeka - Croatia: Intech. Cap. 5, p. 74-88.

SILVERSTEIN, R. M. WEBSTER, F. X. KIEMLE, D. J. (2006). Identificação espectrométrica de compostos orgânicos. 7 ed. Rio de Janeiro: LTC.

TOZATTI, C.S.S. (2016). Sintese, Análise Conformacional e Avaliação Biológia de Hidrazonas Derivadas de Acetofenonas Substituídas e da Naringerina. 308f. Tese de Doutorado em Química. Instituto de Química, Universidade Federal de Mato Grosso do Sul, Campo Grande.

WARAD, I. (2013). Metal ions as Antitumor Complexes-Review. Journal of Materials and Environmental Science. v.4, n. 4 , p. 543-547. 
Autor1, Autor2, Autor3

190 UNESUM-Ciencias. Publicación cuatrimestral. Vol. 1, Año 2017, No. 1 (Abril) 